\title{
Influence of Berdan and Boxer Primer Spit-Hole Diameter on 7.62-mm Cartridge Performance
}

\author{
by John J. Ritter
}

ARL-TR-6968

June 2014 


\section{NOTICES}

\section{Disclaimers}

The findings in this report are not to be construed as an official Department of the Army position unless so designated by other authorized documents.

Citation of manufacturer's or trade names does not constitute an official endorsement or approval of the use thereof.

Destroy this report when it is no longer needed. Do not return it to the originator. 


\section{Army Research Laboratory}

Aberdeen Proving Ground, MD 21005-5066

\section{Influence of Berdan and Boxer Primer Spit-Hole Diameter on 7.62-mm Cartridge Performance}

John J. Ritter

Weapons and Materials Research Directorate, ARL 


\section{REPORT DOCUMENTATION PAGE}

Form Approved OMB No. 0704-0188

Public reporting burden for this collection of information is estimated to average 1 hour per response, including the time for reviewing instructions, searching existing data sources, gathering and maintaining the data needed, and completing and reviewing the collection information. Send comments regarding this burden estimate or any other aspect of this collection of information including suggestions for reducing the burden, to Department of Defense, Washington Headquarters Services, Directorate for Information Operations and Reports (0704-0188), 1215 Jefferson Davis Highway, Suite 1204, Arlington, VA 22202-4302. Respondents should be aware that notwithstanding any other provision of law, no person shall be subject to any penalty for failing to comply with a collection of information if it does not display a currently valid OMB control number.

PLEASE DO NOT RETURN YOUR FORM TO THE ABOVE ADDRESS.

$\begin{aligned} & \text { 1. REPORT DATE (DD-MM- } Y Y Y Y) \\ & \text { June } 2014\end{aligned}$
$\begin{aligned} & \text { 4. TITLE AND SUBTITLE } \\ & \text { Final }\end{aligned}$
$\begin{aligned} & \text { Influence of Berdan and Boxer Primer Spit-Hole Diameter on 7.62-mm Cartridge } \\ & \text { Performance }\end{aligned}$

Performance

3. DATES COVERED (From - To)

December 2013-January 2014

5a. CONTRACT NUMBER

5b. GRANT NUMBER

5c. PROGRAM ELEMENT NUMBER

6. AUTHOR(S)

John J. Ritter

5d. PROJECT NUMBER

5e. TASK NUMBER

5f. WORK UNIT NUMBER

8. PERFORMING ORGANIZATION REPORT NUMBER

U.S. Army Research Laboratory

ATTN: RDRL-WML-D

Aberdeen Proving Ground, MD 21005-5066

9. SPONSORING/MONITORING AGENCY NAME(S) AND ADDRESS(ES)

ARL-TR-6968

10. SPONSOR/MONITOR'S ACRONYM(S)

11. SPONSOR/MONITOR'S REPORT

NUMBER(S)

\section{DISTRIBUTION/AVAILABILITY STATEMENT}

Approved for public release; distribution is unlimited.

\section{SUPPLEMENTARY NOTES}

\section{ABSTRACT}

The U.S. Army Research Laboratory (ARL) conducted a study to examine the effects of varying a small caliber (7.62 mm) cartridge's spit-hole on the interior and exterior ballistic performance of the cartridge. Along with standard Boxer primers, a Berdan style primer configuration is evaluated. Performance metrics evaluated were cartridge pressure, primer pocket pressure, and muzzle velocity.

\section{SUBJECT TERMS}

M80, primer force, spit-hole, interior ballistics, Berdan primer, Boxer primer

\section{SECURITY CLASSIFICATION OF:}

\begin{tabular}{l|l|l|}
\hline a. REPORT & b. ABSTRACT & c. THIS PAGE \\
Unclassified & Unclassified & Unclassified \\
\hline
\end{tabular}

\begin{tabular}{c|c}
$\begin{array}{c}\text { 17. LIMITATION } \\
\text { OF ABSTRACT }\end{array}$ & $\begin{array}{r}\text { 18. NUMBER } \\
\text { OF PAGES }\end{array}$ \\
UU & 21 \\
\hline
\end{tabular}

19a. NAME OF RESPONSIBLE PERSON

John J. Ritter

19b. TELEPHONE NUMBER (Include area code) 410-278-6180 


\section{Contents}

List of Figures $\quad$ iv

List of Tables

$\begin{array}{ll}\text { 1. Introduction } & 1\end{array}$

2. Approach 2

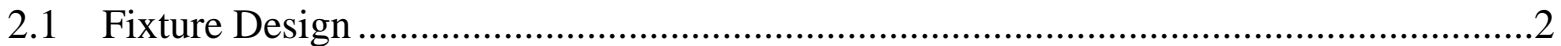

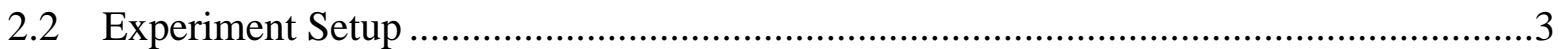

3. Results $\quad 4$

$\begin{array}{lr}\text { 4. Conclusions } & 9\end{array}$

5. References $\quad 11$

$\begin{array}{ll}\text { List of Symbols, Abbreviations, and Acronyms } & 13\end{array}$

$\begin{array}{ll}\text { Distribution List } & 14\end{array}$ 


\section{List of Figures}

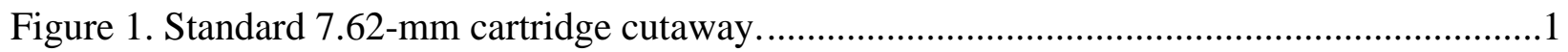

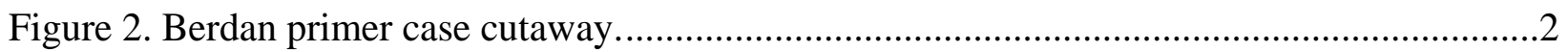

Figure 3. Detail view of 7.62-mm instrumented barrel and breech...............................................2

Figure 4. (a) Primer pocket with enlarged spit-hole (0.110 in diameter), (b) standard M80 primer pocket, (c) Berdan style primer pocket with two spit-holes, each 0.055 in diameter

Figure 5. Pressure data for various spit-hole configurations. ............................................................

Figure 6. Pressure and force data for Berdan style spit-hole.........................................................6

Figure 7. Zoomed-in initial force data for Berdan style spit-hole. …................................................

Figure 8. Pressure and force data for enlarged spit-hole. ................................................................8

Figure 9. Zoomed-in force data for enlarged spit-hole..................................................................9

\section{List of Tables}

Table 1. Performance of various primer configurations. 


\section{Introduction}

The U.S. Army Research Laboratory (ARL) has recently employed its primer force measurement apparatus to evaluate 7.62-millimeter (mm) cartridge interior ballistic (IB) performance (1). These experiments investigated the influence of reducing the spit-hole area by half on the interior and exterior ballistics performance of an otherwise standard M80 cartridge. For the current investigation researchers will examine performance differences between various Boxer and Berdan style primer configurations. To date, very little experimentation has been done to correlate performance between the two primer types, although both are widely circulated. The only publication available that made such an attempt was a study that investigated primer gas and particulate matter penetration into propellant beds using various primers (2). However, this study did not evaluate overall performance of cartridges with the differing primer configurations. Furthermore, the study's main focus was on the primer material composition as opposed to the primer's configuration (i.e., Berdan versus Boxer).

Boxer and Berdan primers differ in the configuration of their respective anvil, which is used as a pinch point to initiate the primer's energetic material. In a Boxer primer the primer cup contains the primer material along with the anvil as a single unit. Once initiated, the products of combustion are then forced through a single, centrally located spit-hole that connects the primer pocket to the main propellant chamber (figure 1). In a Berdan primer the anvil is an integral part of the cartridge case, thus the primer is only composed of the cup and energetic material. Since the anvil is located along the center axis of the case, two smaller spit-holes are located on either side of the anvil in the primer pocket (figure 2). The primary advantage of a Berdan primer is that they are less expensive than a Boxer primer due to their reduced complexity.

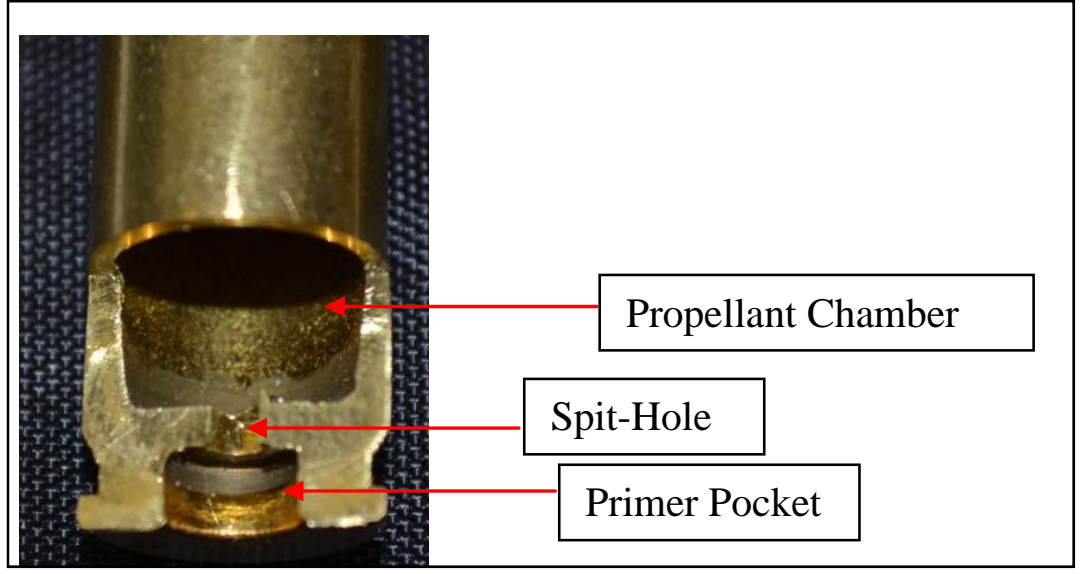

Figure 1. Standard 7.62-mm cartridge cutaway. 


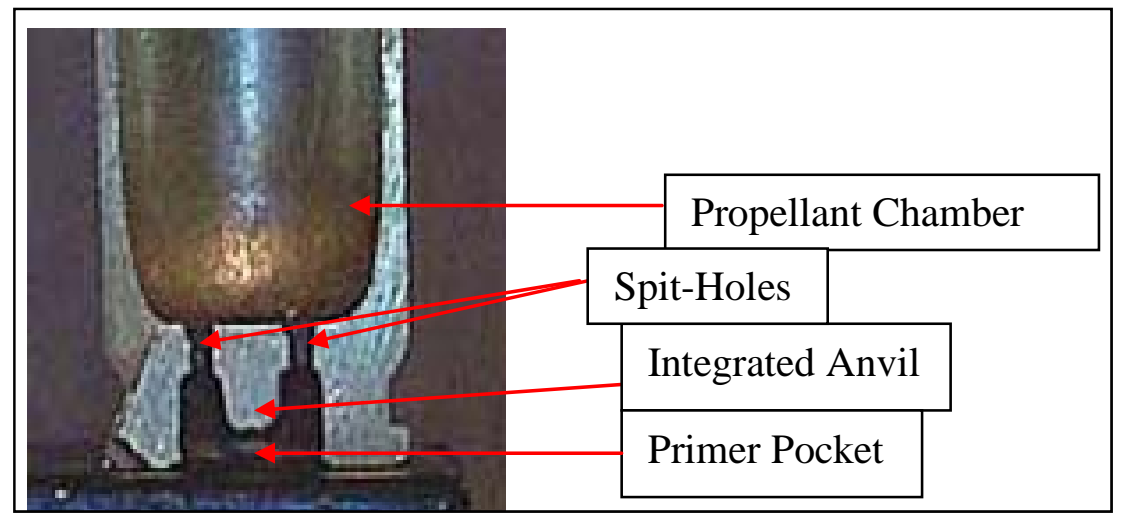

Figure 2. Berdan primer case cutaway.

\section{Approach}

\subsection{Fixture Design}

The breech apparatus employed for the experiments is the ARL-designed fixture that measures primer force throughout the IB cycle. The barrel is a 7.62-mm Mann barrel rifled to match an M14 with an overall length of 22.25 inches (in) (3). The midchamber pressure transducer, Kistler Model 6215 (4), is consistent with previous experiments. Pressure is measured through a 3/32-in hole drilled into the cartridge case forward of the midpoint, and case holes are sealed with 1-milthick DuPont Kapton* tape. The force transducer selected is the Kistler Model 9031A Load Washer (5). Force transducer selection was driven by the anticipated load and necessity of an annular design to allow passage of the firing pin through the transducer. Figure 3 shows the configuration of the primer force experiment.

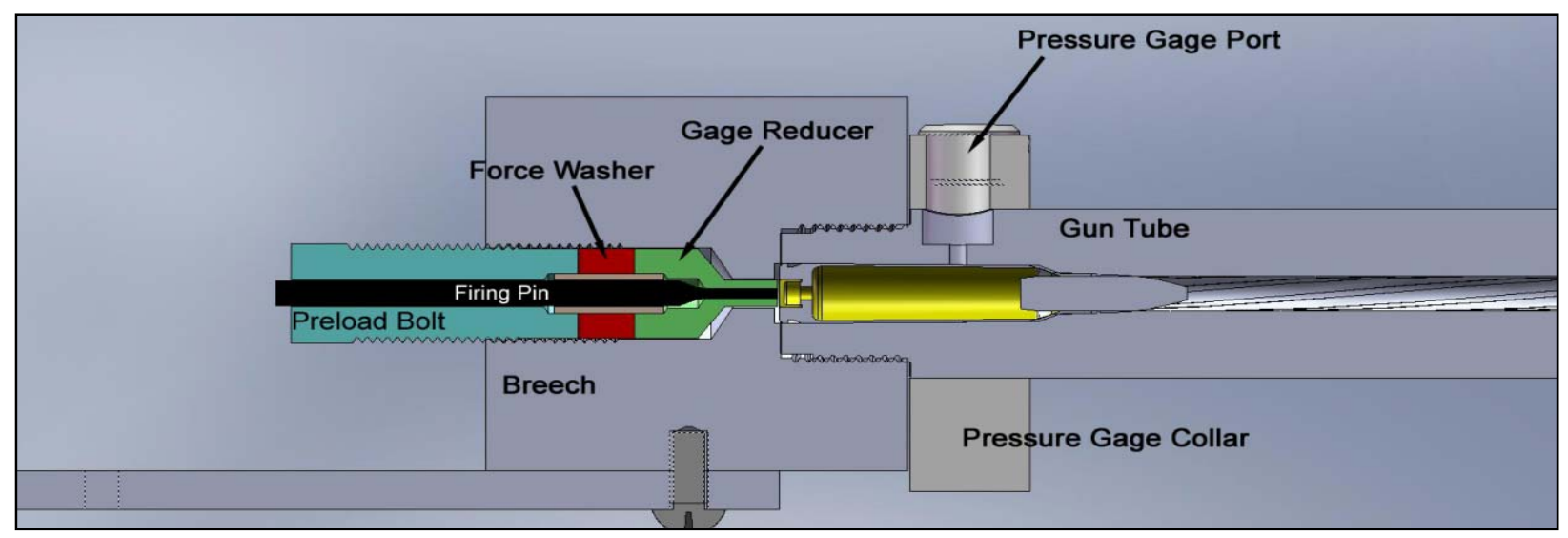

Figure 3. Detail view of 7.62-mm instrumented barrel and breech.

\footnotetext{
* Kapton is a registered trademark of E.I. du Pont de Nemours and Company.
} 


\subsection{Experiment Setup}

Experiments were performed to investigate the role the spit-hole plays in overall cartridge performance. The nominal M80 spit-hole diameter is 0.078 in (6), but for our experiment the hole was enlarged to 0.110 in, increasing the area by $98.9 \%$. The Berdan style configuration employed two spit-holes each with a diameter of 0.055 in, resulting in an overall area nearly equal to the standard M80 spit-hole. In order to evaluate configuration effects, and not the components, the Berdan style setup used the same No. 34 Boxer primer as the enlarged spit-hole configuration. The flow of primer products of combustion into the main propellant chamber should be similar to a true Berdan case. The Berdan style cases were constructed from undrilled 7.62-mm brass with the spit-holes drilled 0.0725 in from the cartridge's center axis. Figure 4 illustrates the primer pockets for the three configurations. Note that the Berdan style pocket in the figure has a small dimple in the center that was part of the blank case prior to drilling the spit-holes. This is an inward dimple and not an anvil. Special consideration was taken when loading the No. 34 primer into the Berdan style pocket so that none of the three anvil "legs" covered the spit-holes. This gave confidence that the cartridge would perform consistently and with the best possible primer product flow into the propellant bed.

Standard M80's have been recently evaluated and their data will be compared with the current experiments (1). In the interest of consistency, the propellant and projectiles all come from the same lot of M80 cartridges used for the baseline data. The primers in the nonstandard M80 configurations are No. 34 primers from lot LC-08E720-252. Primer force data is recorded as arbitrary units (a.u.), not pressure, in an effort to distinguish the graphical results from the midcase pressure results. For conversion purposes, 1 a.u. is equal to $400 \mathrm{lbf}$. All graphs $\mathrm{t}_{0}$ is set as the initial peak output of the primer. Pressure and force data is reported as an eight-shot average.

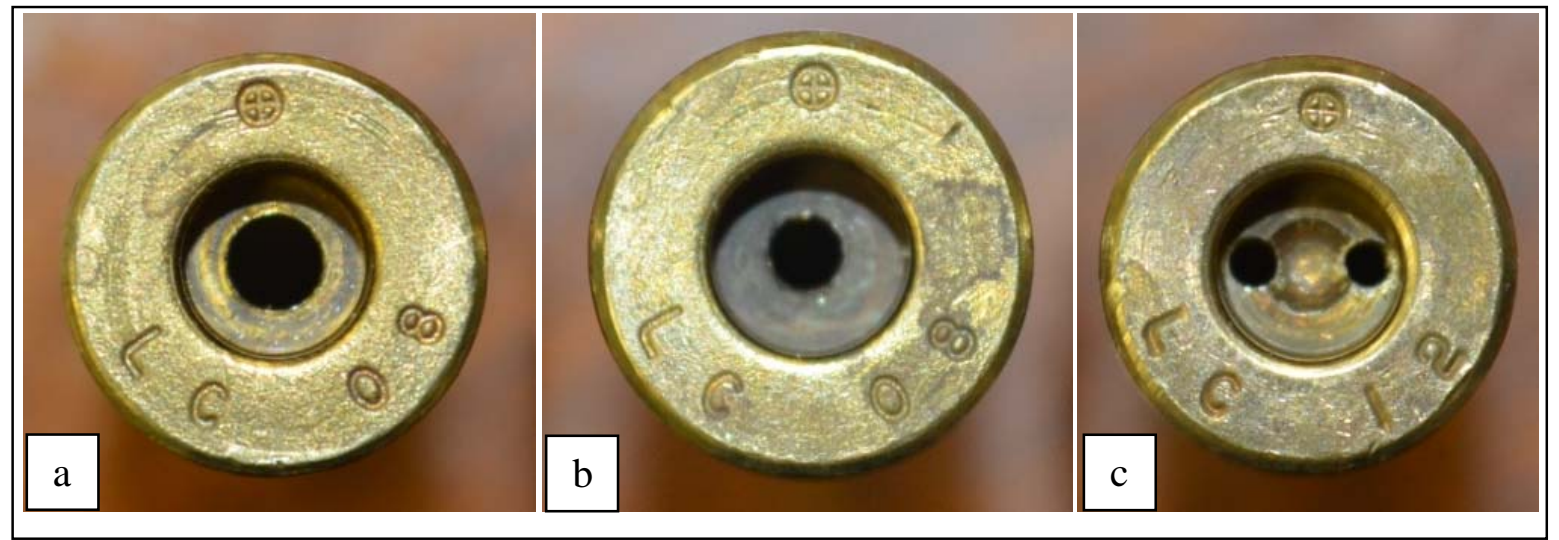

Figure 4. (a) Primer pocket with enlarged spit-hole (0.110 in diameter), (b) standard M80 primer pocket, (c) Berdan style primer pocket with two spit-holes, each 0.055-in diameter. 


\section{Results}

An overview of the data reveals the standard M80 showing the best performance with regards to muzzle velocity; however, the performance differences between the various cartridge configurations are not statistically significant (table 1). Data was also included for a smaller diameter spit-hole (0.005-in diameter) configuration from a previous experiment (1) in addition to the enlarged diameter and Berdan style spit-hole configuration of this experiment.

Table 1. Performance of various primer configurations.

\begin{tabular}{|c|c|c|c|c|}
\hline & \multicolumn{4}{|c|}{ M80 Muzzle Velocity and Peak Pressure } \\
\hline & Baseline $^{\mathrm{a}}$ & Small Boxer $^{\mathrm{a}}$ & Large Boxer & Berdan \\
\hline Average (m/s) & 844.08 & 843.67 & 841.48 & 842.31 \\
\hline $\mathrm{SD}^{\mathrm{c}}(\mathrm{m} / \mathrm{s})^{\mathrm{b}}$ & 5.98 & 4.17 & 6.57 & 4.56 \\
\hline $\left.\mathrm{P}^{\mathrm{d}} \mathrm{Max}^{\mathrm{b}} \mathrm{ksi}\right)^{\mathrm{e}}$ & 50.65 & 50.12 & 49.55 & 49.77 \\
\hline $\mathrm{SD}^{\mathrm{c}}(\mathrm{ksi})^{\mathrm{e}}$ & 1.31 & 1.03 & 1.54 & 0.61 \\
\hline
\end{tabular}

${ }^{\mathrm{a}}$ Data from ARL-TR-6785 (1).

${ }^{\mathrm{b}}$ Meters per second

'Standard deviation.

${ }^{\mathrm{d}}$ Pressure.

${ }^{\mathrm{e}}$ Thousand pounds per square inch.

Examining the pressure-time curves can provide insight into the IB behavior of a particular cartridge. As depicted in figure 5, there is little variation in the pressure-time curves between the different spit-hole configurations. The standard M80 cartridge showed slightly higher peak pressures, but only 1100 pounds per square inch (psi) over the lowest performing large Boxer configuration. This translated to a muzzle velocity difference of $2.6 \mathrm{~m} / \mathrm{s}$, also the largest difference between configurations. All of these differences are within one standard deviation, and are not significant. 


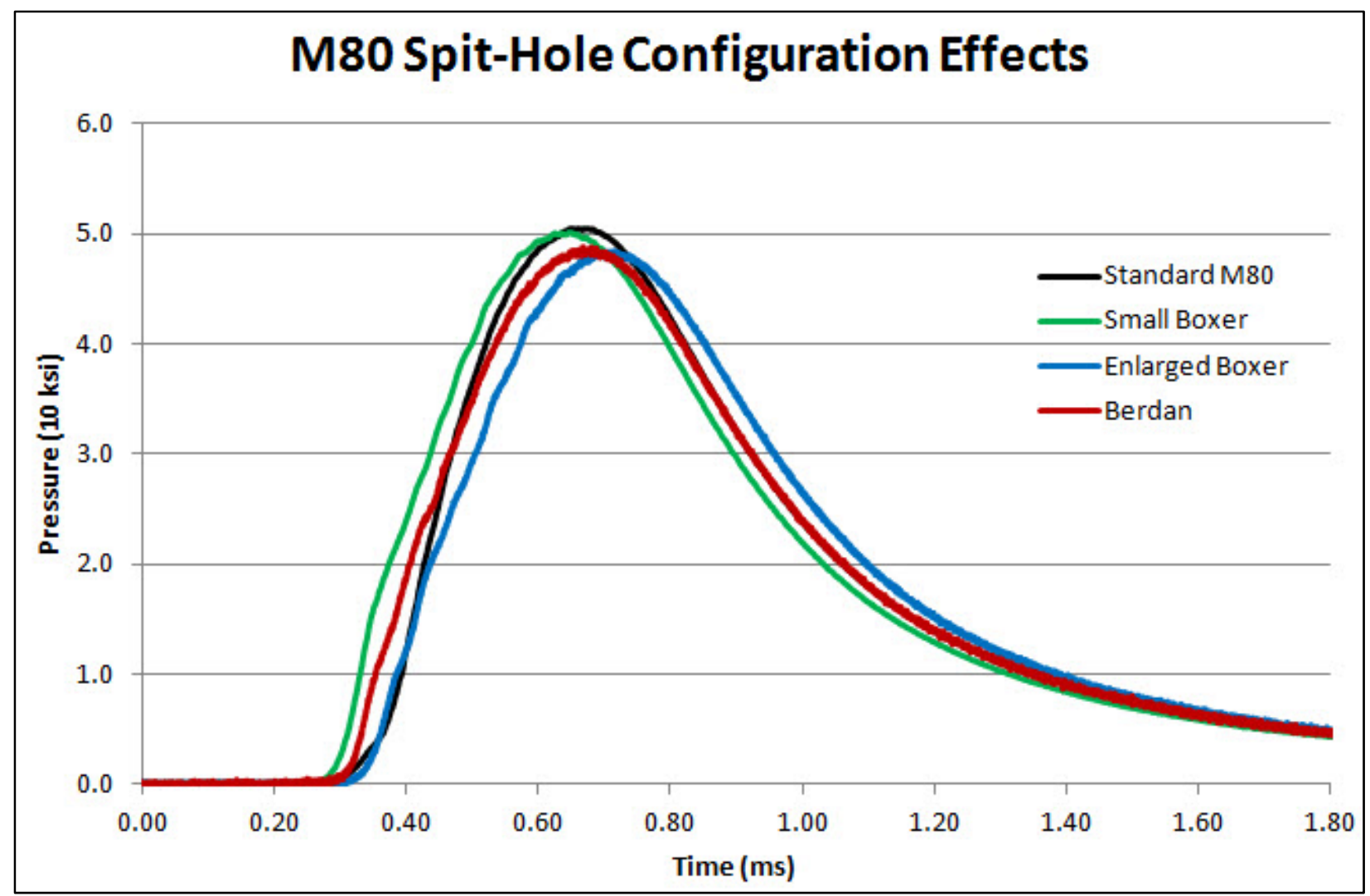

Figure 5. Pressure data for various spit-hole configurations.

A closer examination of the Berdan style spit-hole data against the standard M80 shows virtually no change in the initial primer output, and very little change in the pressure output (figures 6 and 7). The slight difference noted showed the Berdan style spit-hole produces pressure sooner in the IB cycle, but that pressure has a lower pressurization rate (more gradual slope) and a lower peak pressure than the M80 (49.8 ksi versus $50.6 \mathrm{ksi}$ ). All of this translates into a slightly diminished muzzle velocity. If there is one area that the Berdan style primer may outperform the standard M80 it is with its consistency. The standard deviation of both the muzzle velocity and peak pressure was lower in the Berdan. However, none of the configurations explored had particularly bad standard deviations. 


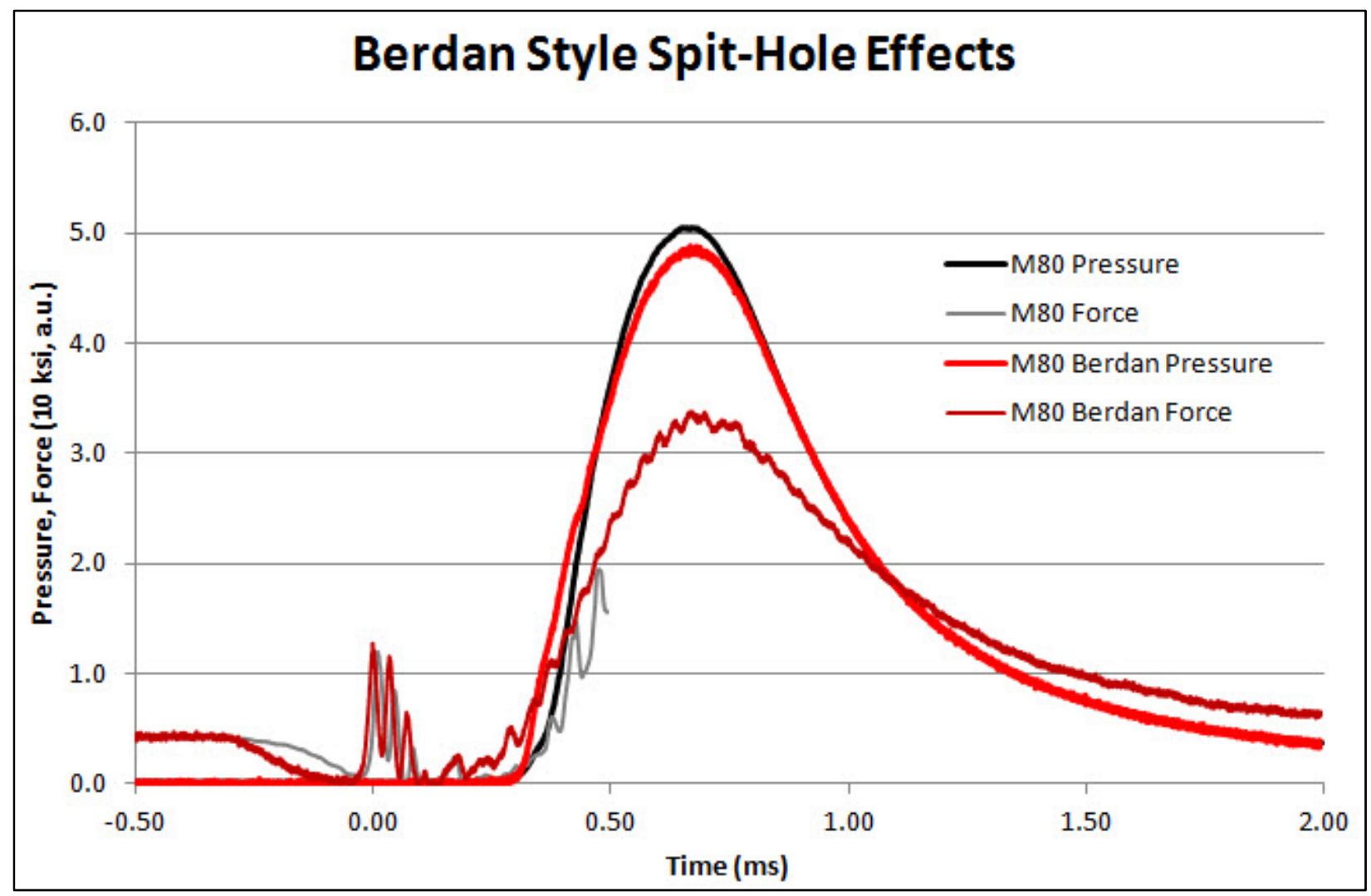

Figure 6. Pressure and force data for Berdan style spit-hole. 


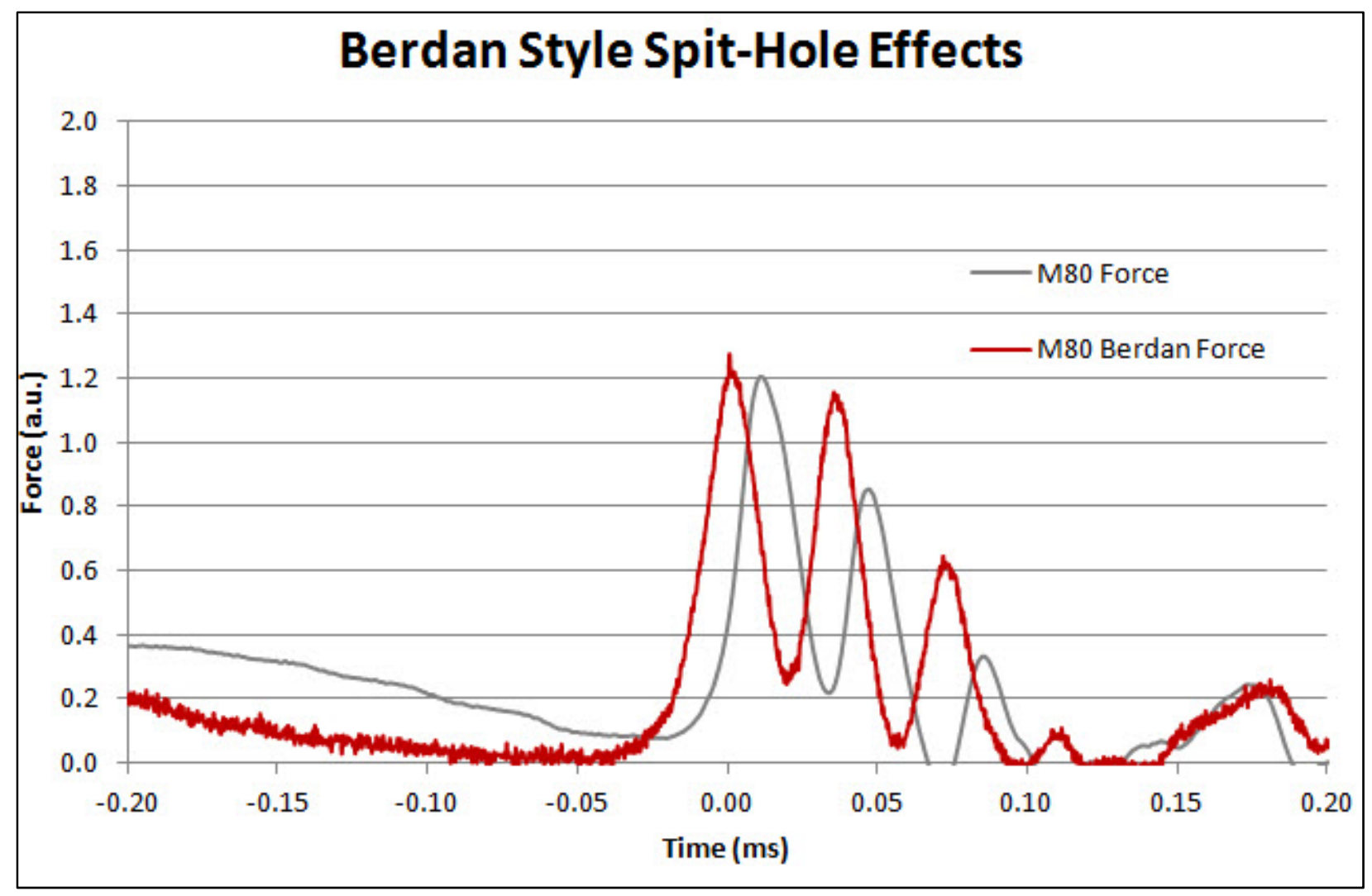

Figure 7. Zoomed-in initial force data for Berdan style spit-hole. 
Comparing the enlarged spit-hole to the standard M80 reveals that there is a slight decline in performance (figures 8 and 9). The initial primer force output is reduced by roughly 50\% because the products of combustion have twice the available area to transition into the propellant bed. The enlarged area likely results in less propellant bed penetration by the hot particles and gases of the primer, thus altering the burning profile of the propellant. The initial pressure-time curve mimics the standard M80; however, it deviates around $20 \mathrm{ksi}$, and the pressurization rate is reduced in the larger spit-hole configuration. This deviation results in lower overall peak pressure and lower muzzle velocity, by 1100 psi and $2.6 \mathrm{~m} / \mathrm{s}$, respectively.

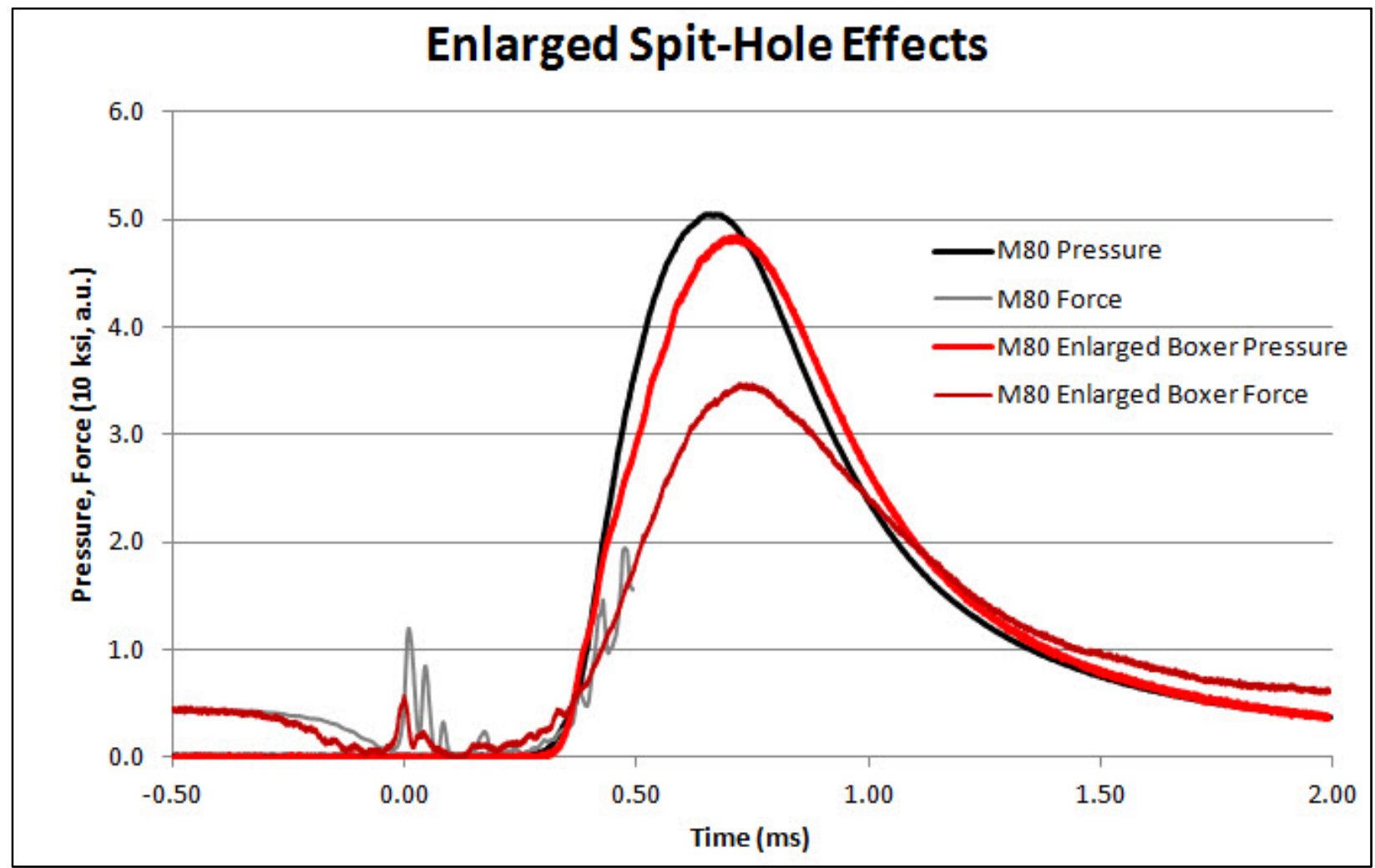

Figure 8. Pressure and force data for enlarged spit-hole. 


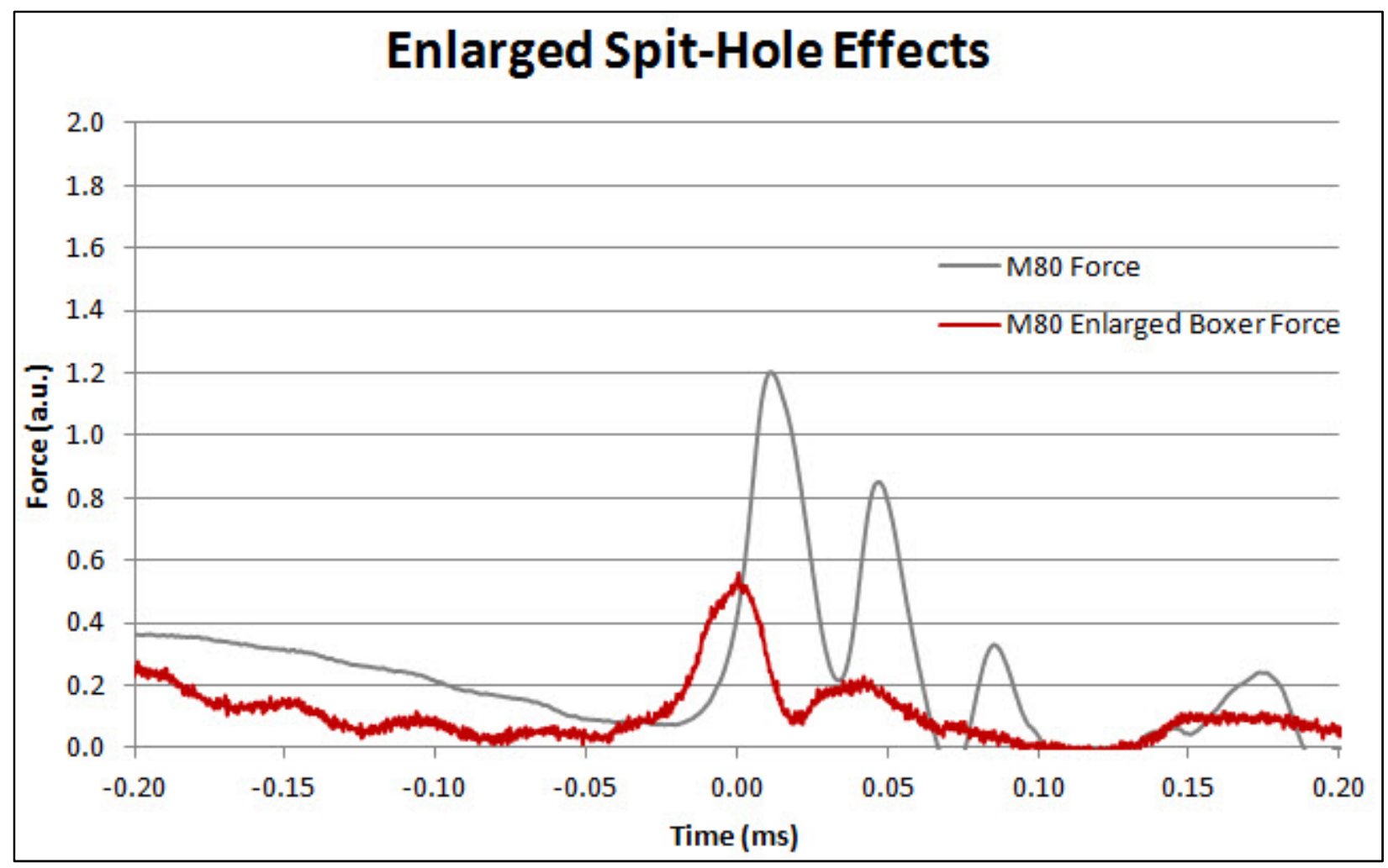

Figure 9. Zoomed-in force data for enlarged spit-hole.

The data indicates alterations to the M80's spit-hole area and configuration does not affect performance significantly. The current design is sufficient, if not optimized, and changes are unlikely to return significant performance gains. Projectile, propellant, and primer design changes would all have a much greater impact on the performance than spit-hole design.

\section{Conclusions}

The ARL designed 7.62-mm force measurement breech was employed to characterize the effects of changing the spit-hole design on the IB performance of an M80 cartridge. Doubling the area of the spit-hole or incorporating a Berdan style spit-hole with the same total area as a standard M80 showed minimal effects on the overall performance. The standard M80 showed the best results.

Altering the spit-hole configuration will change the force initially seen in the primer pocket. A hole with less area for the primer products to pass through to the propellant bed will generate higher initial primer forces. Likewise, a larger spit-hole will result in lower initial primer forces. Ultimately, these changes alter how the products of primer combustion permeate into the 
propellant bed. Nevertheless, the resulting effects appear to be minor, and all configurations examined had a detrimental effect on performance. This leads one to conclude that the spit-hole on the M80 cartridge is both optimally designed and robust. 


\section{References}

1. Ritter, J. J. Spit-Hole Effects on the Ballistics of a 7.62-mm Cartridge; ARL-TR-6785; U.S. Army Research Laboratory: Aberdeen Proving Ground, MD, February 2014.

2. Stephenson, S. S.; Rye, A. R. Primer Gas and Hot Particle Penetration in Granular Propellant Beds in Small Arms Ammunition. Proceedings of the $9^{\text {th }}$ International Symposium on Ballistics; Defence Science and Technology Organization Weapons Systems Research Laboratory: Salisbury, South Australia, April 1986.

3. M14 Barrel, Drawing 7790190, Rev R, January 1986.

4. Kistler Operating Instructions, Quartz High-Pressure Sensor Type 6215, Kistler Group. http://www.kistler.com/us/en/product/pressure/6215. Winterthur, Switzerland (accessed January 2008).

5. Kistler Product Data Sheet, Load Washers, Type 9001A...9071A, Kistler Group, Winterthur, Switzerland. http://www.kistler.com/us/en/product/force/9001A (accessed January 2009).

6. Case (7.62 mm), Drawing 10521997, Rev AA, November 2001. 
INTENTIONALLY LEFT BLANK. 


\section{List of Symbols, Abbreviations, and Acronyms}

$\begin{array}{ll}\text { ARL } & \text { U.S. Army Research Laboratory } \\ \text { a.u. } & \text { arbitrary unit } \\ \text { IB } & \text { interior ballistics } \\ \text { in } & \text { inch } \\ \text { ksi } & \text { thousand pounds per square inch } \\ \text { lbf } & \text { pound force } \\ \text { mm } & \text { millimeter } \\ \text { m/s } & \text { meters per second } \\ \text { No. } & \text { number } \\ \text { P } & \text { pressure } \\ \text { psi } & \text { pounds per square inch } \\ \text { SD } & \text { standard deviation }\end{array}$


RDRL WML H

T EHLERS

T FARRAND

L MAGNESS

J NEWILL

RDRL WMM C

P KASTE 